ISSN: 0514-7336

DOI: http://dx.doi.org/10.14201/zephyrus20137295111

\title{
UTILIZACIÓN DE INSTRUMENTOS DE CONCHA PARA LA REALIZACIÓN DE ACTIVIDADES PRODUCTIVAS EN SOCIEDADES TRIBALES COMUNITARIAS DEL SUR DE LA PENÍNSULA IBÉRICA. EL EJEMPLO DE CAMPO DE HOCKEY (SAN FERNANDO, CÁDIZ) Y SET PARRALEJOS (VEJER DE LA FRONTERA, CÁDIZ)
}

\section{Using shell tools for productive activities in tribal communal societies from southern Iberia. The example of Campo de Hockey (San Fernando, Cádiz) and SET Parralejos (Vejer de la Frontera, Cádiz)}

David Cuenca Solana*, Juan Jesús Cantillo Duarte**, Eduardo Vijande Vila**, Manuel Montañés CABallero***, Ignacio Clemente Conte**** y Antonio Villalpando Moreno***

* Centre de Recherche en Archéologie, Archéosciences et Historie. 263. Avenue du général Leclerc. Campus de Beaulieu, bât.24-25. 35042 Rennes. CEDEX.Correo-e: david.cuencasolana@univrennes1.fr

** Area de Prehistoria. Universidad de Cádiz. Avda. GómezUlla, s/n. Cádiz. Correo-e: jesus.cantillo@uca.es; eduardo.vijande@uca.es

*** Arqueólogo. GeHAARQueología, S. C. P. SN. C/ Alarcón, 6. 11170 Medina Sidonia (Cádiz). Correo-e: gehaarqueologia@hotmail.com

**** Dpto. de Arqueología y Antropología. IMF-CSIC. Cl Egipcíaques, 15. 08001 Barcelona. Correo-e: ignacio@imf.csic.es

Recepción: 05/06/2012; Revisión: 6/11/2012; Aceptación: 11/3/2013

BIBLID [0514-7336 (2013) LXXII, julio-diciembre; 95-111]

\footnotetext{
RESUMEN: La metodología de análisis funcional ha sido aplicada principalmente para el estudio de instrumentos líticos, mientras que su utilización ha sido muy marginal para el estudio de los instrumentos de trabajo constituidos con materia de origen animal. Sin embargo, a través de la aplicación de esta metodología ha sido posible documentar diez instrumentos de concha en los yacimientos de Campo de Hockey y SET Parralejos, ocupaciones del IV-V milenio a. C. situadas en la banda atlántica de Cádiz. La interpretación de las huellas de uso desarrolladas en las superficies de estas conchas ha permitido establecer algunas hipótesis acerca de su participación activa en diferentes procesos productivos relacionados con el procesado de materias de origen animal y vegetal. Estos resultados han posibilitado establecer una relación entre el uso de estos instrumentos de concha y la eficacia de otros instrumentos empleados en las estrategias de subsistencia, contribuyendo a ampliar el conocimiento acerca de los medios de trabajo de estas sociedades tribales comunitarias.

Palabras clave: Análisis funcional. Arqueomalacología. Huellas de uso. Sociedades tribales. Península Ibérica.

ABSTRACT: Functional analysis has focused mainly on the study of lithic instruments and to a lesser extent instruments made on animal materials. Using functional analysis we identified ten shell tools from
} 
the archaeological sites of Campo de Hockey and SET Parralejos, located in the Atlantic coast of Cádiz (southern Spain). Both sites date to the IV-V millennium BC. The interpretation of use wear present on the surface of the shells has enabled us to establish hypotheses about their use in different productive activities related to processing animal and vegetable materials. The results of this research will help establish a relationship between shell instrument use and a more efficient use of tools in subsistence strategies, as well as increase our knowledge about the mains of production of these tribal communal societies.

Key words: Functional analysis. Archaeomalacology. Signs of use. Tribal communal societies. Iberian Peninsula.

\section{Introducción ${ }^{1}$}

La documentación de evidencias de utilización instrumental de restos arqueomalacológicos en contextos de cronología neolítica no es algo novedoso en Europa. Sin embargo, en el caso de SET Parralejos y Campo de Hockey se trata de la primera identificación de este tipo en el sur de la Península Ibérica realizada a través de metodología de análisis funcional, es decir, mediante la aplicación de metodología de observación microscópica y macroscópica y la experimentación analítica (González Urquijo e Ibáñez Estévez, 1994). Hasta este momento, a través de metodología de análisis funcional ha sido posible documentar el uso de este tipo de tecnología en contextos localizados en el norte de la costa atlántica de la Península Ibérica como Santimamiñe, Vizcaya ${ }^{2}$ (Cuenca et al., 2010; Gutiérrez Zugasti et al., 2011) y en la costa mediterránea, como en La Draga, Gerona (Clemente y Cuenca, 2011).

En estos contextos se ha puesto en evidencia la utilización de fragmentos o conchas completas de Mytilus galloprovincialis, Ruditapes decussatus, Callista chione u Ostrea edulis, para realizar diferentes actividades productivas. En el caso de La Draga (Banyoles,

\footnotetext{
${ }^{1}$ Los autores desean agradecer al IIIPC de la Univ. de Cantabria la financiación y apoyo logístico para realizar el análisis del material, al Grupo de Investigación PAI-HUM440 de la Junta de Andalucía y a EDP Renovables, S. A. la financiación para realizar respectivamente las intervenciones arqueológicas en Campo de Hockey y SET Parralejos. El primer firmante ha disfrutado de un contrato predoctoral de la Univ. de Cantabria y de una beca postdoctoral de Fondation Fys.

${ }^{2}$ Cuenca, D.: Las 'tecnologías invisibles' en los grupos de cazadores recolectores del litoral durante los inicios del Holoceno (9500-5000 uncal BP) en la región Cantábrica. Utilización de las conchas de molusco en la realización de actividades productivas, trabajo de investigación de tercer ciclo inédito, presentado en 2009 en la Univ. de Cantabria.
}

Girona) el análisis funcional mostró la especialización de los instrumentos de Mytilus galloprovincialis en trabajos relacionados con la obtención y procesado de fibras vegetales, mientras que las conchas de Callista chione fueron usadas para procesar piel (Clemente y Cuenca, 2011). En Santimamiñe (Kortezubi, Vizcaya), la utilización de las conchas de Mytilus galloprovincialis estuvo orientada a procesar una materia blanda de origen animal. Aquí además se ha podido documentar el uso de fragmentos de Ruditapes decussatus y Ostrea edulis para tratar vegetales no leñosos y piel/cuero ${ }^{3}$ (Cuenca et al., 2011; Gutiérrez Zugasti et al., 2011).

Desde otras perspectivas de análisis, en este caso a través del empleo de la observación macroscópica, también se han documentado instrumentos de concha en contextos de esta cronología en el sur de la Península Ibérica (Maicas Ramos, 2008). En este sentido, consideramos que el empleo de analíticas basadas únicamente en la observación macroscópica dificulta el establecimiento de hipótesis que relacionen las huellas de uso con los procesos productivos desarrollados con el utillaje. Otros investigadores han tratado de establecer hipótesis sobre la función de estos instrumentos a través de la experimentación replicativa o prospectiva (Vigie y Courtin, 1986) o de los paralelos etnográficos (Vigie, 1987). Estas aportaciones iniciales han sido imprescindibles para abrir una importante vía de análisis, contribuyendo a ampliar la visión acerca del instrumental utilizado por algunos grupos humanos prehistóricos para el desarrollo de sus actividades productivas. A pesar de ello, es indudable que son las aplicaciones realizadas desde el análisis de las huellas de uso -macro- y microscópicas- generadas en estos instrumentos las que pueden aportar información más relevante para ampliar el conocimiento acerca de las formas de vida de las formaciones económico-sociales prehistóricas. Tanto

$$
{ }^{3} \text { Cf. n. } 2 .
$$


a través de un mejor conocimiento del utillaje empleado para la realización de las actividades productivas, como de la reconstrucción de algunos de estos procesos, a partir del análisis de los instrumentos de trabajo empleados para su desarrolló . De esta forma, nuevas aplicaciones de esta metodología sobre conjuntos arqueomalacológicos van ampliando progresivamente el marco geográfico y cronológico en el que se documenta este tipo de utilizaciones (Cristiani et al., 2005; Mansur y Clemente, 2009; Lammers, 2008). Los resultados obtenidos muestran que existe una gran variedad de actividades productivas y materias procesadas con instrumentos de concha. Sin embargo, desde el punto de vista arqueológico todas estas técnicas y usos solo son posibles de reconocer desde el análisis funcional (Semenov, 1964). Así a través de la confronta-

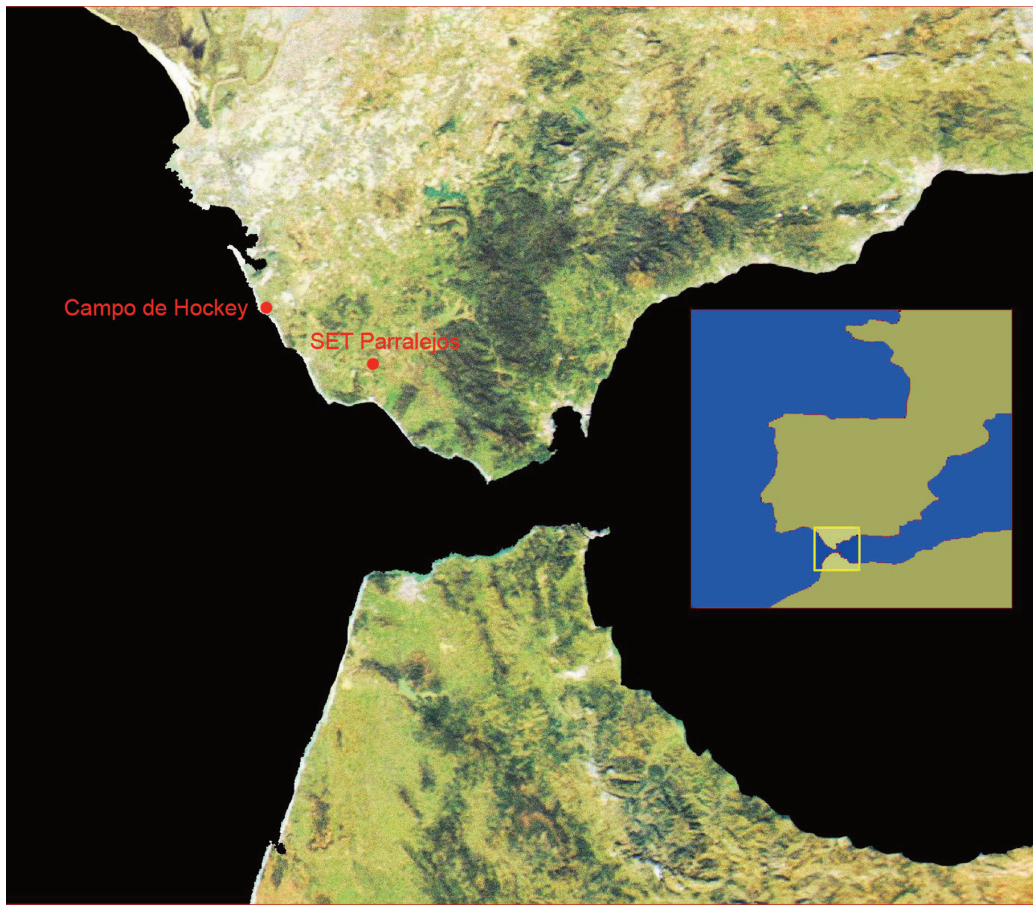

FIG. 1. Localización de Campo de Hockey y SET Parralejos. ción de los resultados experimentales con el material arqueológico, a partir del campo de inferencia generado por el control de las distintas variables que intervienen en la formación de las huellas de uso, podremos intentar reconstruir procesos de manufactura y/o uso de instrumentos de concha ${ }^{5}$ (Clemente y Cuenca, 2011; Cuenca et al., 2010; Gutiérrez Zugasti et al., 2011) contribuyendo de esta forma a ampliar nuestro conocimiento sobre las formas de vida y de producción de las formaciones económico-sociales que los utilizaron para asegurar su reproducción biológica. Finalmente la incorporación de toda esta información bajo una perspectiva crítica para el análisis de sociedades del pasado debe contribuir a modificar la visión tradicional de los moluscos de forma casi exclusiva como desperdicios alimenticios y elementos de adorno (Cuenca Solana et al., 2010) ${ }^{6}$.

${ }^{4}$ Cuenca, D.; Clemente, I.; Oliva, M. y GutiérrezZugasti, I.: "Estudio de la manufactura y/o uso de instrumentos de trabajo y elementos de adorno de concha a partir del análisis funcional”. En Archaeofauna. Actas de la II reunión de Arqueomalacología de la Península Ibérica (Barcelona 19-20 mayo 2011), en prensa.

${ }^{5}$ Cf. n. 2.

${ }^{6} \mathrm{Cf}$. n. 4.

\section{Los yacimientos arqueológicos. Contextualización y recursos marinos}

\subsection{El yacimiento de Campo de Hockey (San Fernando, Cádiz) y las evidencias arqueomalacológicas}

El yacimiento de Campo de Hockey se localiza en el extremo sur del término municipal de San Fernando (Cádiz), a escasos metros de la línea de costa y sobre una ladera con una altura de entre 12-18 m.s.n.m. (Fig. 1). La insularidad de este territorio durante la Prehistoria reciente es algo que aún se intuye por medio de la observación del cambio de pendiente entre las zonas elevadas de la actual ciudad y las salinas y esteros que la rodean (Arteaga et al., 2008; Alonso et al., 2009).

Este poblado y su necrópolis se enmarcan cronológicamente en un momento de importantes transformaciones. El v milenio a. C. viene caracterizado por el afianzamiento de las prácticas productivas -agrícolas y ganaderas- sobre las predadoras -caza, pesca y recolección-, dando lugar a la implantación de formas de vida aldeanas sedentarias (Vargas, 1987). Necrópolis como la de Campo de Hockey manifiestan una territorialización definitiva del grupo y la 


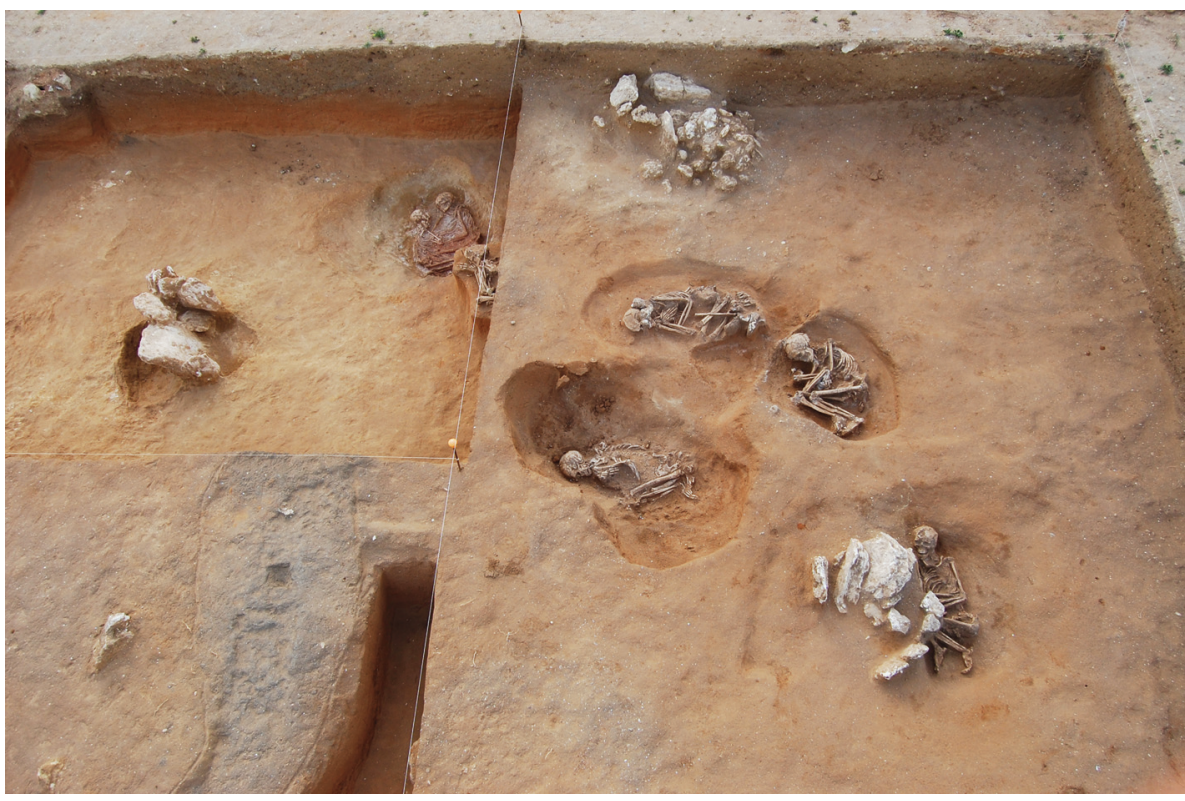

FIG. 2. Vista parcial del yacimiento de Campo de Hockey (Vijande, 2011).

poblado es su extensa necrópolis en la que se han documentado, hasta la fecha, 83 individuos (Fig. 2). Según nuestras estimaciones $1 / 3$ de la necrópolis habría resultado destruida por el rebaje mecánico previo a la construcción de la edificación deportiva, $1 / 3$ se correspondería con el área excavada por nuestro equipo y el último tercio se ha mantenido intacto como "área de reserva arqueológica” conservada bajo el césped del actual estadio deportivo. El elevado número de estructuras funerarias documentadas, unido al buen estado de conservación de los enterramientos,

aparición de nuevas relaciones de producción y reproducción basadas en el linaje. Suponen igualmente una clara muestra del establecimiento de estos grupos en zonas costeras, aunque muy aptas para el desarrollo de las actividades agroganaderas, y de gran importancia para la explotación de los recursos marinos (Vijande, 2011).

Hemos detectado tres zonas claramente diferenciadas dentro de este yacimiento neolítico. En la zona alta se han documentado dos estructuras interpretadas como fondos de cabaña, localizándose una de ellas en el perfil oeste del solar, lo que nos sugiere una extensión del poblado, y más concretamente del área de hábitat, hacia los solares occidentales colindantes. La zona media presenta 5 estructuras circulares a las que por su tipología hemos denominado "pozos". Defendemos una funcionalidad de almacenamiento para estas estructuras siendo imposible, hasta el momento, precisar qué tipo de producto o productos fueron almacenados en su interior. Estos pozos presentan unos diámetros en la boca de entre 4 y $5 \mathrm{~m}$ y una profundidad máxima excavada de 3,70 $\mathrm{m}$-ninguno de ellos ha podido ser excavado íntegramente por problemas de seguridad-, mostrándonos por lo tanto un elevado volumen de almacenamiento. El área más significativa de este son claves para acercarnos al conocimiento de los modos de vida de estas comunidades. De igual manera, el análisis de los objetos exóticos que integran parte del ajuar nos aporta datos de gran interés relativos a las redes de distribución de productos y a las desigualdades sociales existentes.

Este yacimiento constituye un tipo de manifestación funeraria (Fig. 2) prácticamente desconocido en la Baja Andalucía para estas cronologías por diversos motivos. En primer lugar, estamos ante una necrópolis perfectamente planificada, en la que la presencia de túmulos y lajas verticales -a modo de estelas- ha impedido la construcción de unos enterramientos sobre otros. En segundo lugar, frente a los rituales de enterramientos colectivos propios de los monumentos megalíticos, la necrópolis de Campo de Hockey presenta inhumaciones individuales, con los sujetos depositados en posición fetal, y recostados sobre el lado derecho o izquierdo, con las manos ubicadas a la altura del pecho o bajo el rostro. Únicamente se han documentado tres enterramientos dobles y dos triples. Esto ha permitido la constatación de una variada tipología de estructuras funerarias y la localización in situ de los ajuares, lo que nos permite obtener inferencias relativas a las desigualdades sociales entre unos inhumados y 
otros en base a sus ajuares y a la tipología de sus estructuras funerarias?

La elección de este enclave para establecerse no es casual, sino que responde a la presencia de una serie de recursos naturales de gran potencialidad susceptibles de ser explotados. La zona cuenta con suelos del tipo Rincones, de gran valor para el desarrollo de los cultivos y la ganadería (García del Barrio, 1988). Igualmente, son abundantes los cantos de cuarzo, cuarcita y sílex aportados por los cercanos ríos Guadalete, Arillo y San Pedro y que fueron utilizados para la confección de utillaje lítico (Zazo et al., 1987). La industria lítica se halla conformada por pequeños núcleos, lo que genera una industria de muy reducido tamaño. Entre los productos retocados destacamos la localización de taladros, trapecios, truncaduras, segmentos, raspadores, buriles, etc. La significativa presencia de microlitos geométricos probablemente vaya asociada a prácticas cinegéticas. Sorprende la elevada presencia de láminas de borde abatido, así como la documentación de hojas de mediano tamaño cuya procedencia puede resultar alóctona. Por último, debemos hacer hincapié en los numerosos productos que presentan lustre de cereal, constituyendo éste un indicativo más de la importancia de la actividad agrícola para esta comunidad.
En relación al registro cerámico cabe señalar la localización de miles de fragmentos correspondientes a una gran diversidad de formas: ollas, cuencos, platos, vasos, etc. Se observa un predominio mayoritario de los fragmentos lisos frente a los decorados. De estos últimos destaca porcentualmente la decoración de tipo inciso, aunque también disponemos de decoraciones impresas, acanaladas, cardiales, mamelones, asas, cordones aplicados, etc.

La industria ósea se halla escasamente representada y aún se encuentra en fase de estudio. Lo más destacado es la presencia in situ en la parte posterior de algunos cráneos de agujas para el tocado del peinado.

Este registro arqueológico casa a la perfección con las dos dataciones absolutas de $\mathrm{C}^{14}$ de que disponemos hasta el momento y que nos permiten adscribir a este poblado de Campo de Hockey en lo que tradicionalmente se ha denominado como Neolítico medio avanzado. La primera datación se ha realizado sobre una muestra de hueso humano (CNA-360) $5020 \pm 50$ BP, 3948-3708 $2 \sigma$ cal BC; y la segunda sobre concha (CNA-664) $5560 \pm 40 \mathrm{BP}, 4221-3990$ $2 \sigma$ cal BC (Vijande, 2009: 273-274) -ambas calibradas mediante CALIB 5.0 (Stuiver y Reimer, 1993; Stuiver et al. 2005) empleando respectivamente las curvas Intcal04 y Marine04- (Fig. 3).

\begin{tabular}{|c|c|c|c|c|c|c|l|}
\hline Yacimiento & Ref. & Material & Ubicación & BP & cal BC $(1 \sigma)$ & cal BC $(2 \sigma)$ & \multicolumn{1}{|c|}{ Bibliografía } \\
\hline $\begin{array}{c}\text { Campo de } \\
\text { Hockey }\end{array}$ & CNA-360 & Hueso & $\begin{array}{c}\text { Enterramiento doble } \\
\text { en fosa simple }\end{array}$ & $5020 \pm 50$ & $3935 / 3860$ & $3948 / 3708$ & Vijande, 2009 \\
\hline $\begin{array}{c}\text { Campo de } \\
\text { Hockey }\end{array}$ & CNA-664 & Concha & $\begin{array}{c}\text { Enterramiento doble } \\
\text { en túmulo megalítico }\end{array}$ & $5650 \pm 40$ & $4166 / 4036$ & $4221 / 3990$ & Vijande, 2009 \\
\hline $\begin{array}{c}\text { SET } \\
\text { Parralejos }\end{array}$ & CNA-649 & Hueso & Enterramiento en silo & $4610 \pm 50$ & - & $3522 / 3312$ & $\begin{array}{l}\text { Villalpando y Montañés, } \\
\text { en prensa }\end{array}$ \\
\hline $\begin{array}{c}\text { SET } \\
\text { Parralejos }\end{array}$ & CNA-650 & Hueso & Enterramiento en silo & $4480 \pm 50$ & - & $3361 / 3014$ & $\begin{array}{l}\text { Villalpando y Montañés, } \\
\text { en prensa }\end{array}$ \\
\hline $\begin{array}{c}\text { SET } \\
\text { Parralejos }\end{array}$ & CNA-651 & Hueso & Interior silo & $4495 \pm 45$ & - & $3355 / 3086$ & $\begin{array}{l}\text { Villalpando y Montañés, } \\
\text { en prensa }\end{array}$ \\
\hline $\begin{array}{c}\text { SET } \\
\text { Parralejos }\end{array}$ & CNA-652 & Concha & Interior silo & $4930 \pm 50$ & - & $3477 / 3113$ & $\begin{array}{l}\text { Villalpando y Montañés, } \\
\text { en prensa }\end{array}$ \\
\hline
\end{tabular}

FIG. 3. Dataciones absolutas obtenidas en Campo de Hockey y SET Parralejos.

${ }^{7}$ Vijande, E.: Formaciones sociales tribales en la región histórica del Estrecho de Gibraltar (VI-IV milenio a. C.). Los ejemplos de la Cueva de Benzú (Ceuta) y el asentamiento de Campo de Hockey (San Fernando, Cádiz), tesis doctoral inédita presentada en 2010 en la Univ. de Cádiz.
Por último, no podemos olvidar la importancia que para estas sociedades debió tener la explotación de los recursos marinos, sobre todo teniendo en cuenta que vivían rodeados por el mar (Cantillo 


\begin{tabular}{|c|c|c|c|c|c|}
\hline Taxones & \multicolumn{5}{|c|}{ Campo de Hockey } \\
\hline BIVALVOS MARINOS & NR & $\%$ NR & NMI & $\%$ NMI & Peso \\
\hline Acanthocardia tuberculata & 2 & 0,04 & 2 & 0,15 & 11 \\
\hline Aequipecten commutatis & 2 & 0,04 & 2 & 0,15 & 5 \\
\hline Aequipecten sp. & 2 & 0,04 & 2 & 0,15 & 2 \\
\hline Barbatia barbata & 3 & 0,07 & 1 & 0,07 & 3 \\
\hline Bivalvo indeterminado & 6 & 0,14 & 6 & 0,47 & 7 \\
\hline Cerastoderma edule & 12 & 0,29 & 7 & 0,55 & 25 \\
\hline Chlamys sp. & 315 & 7,65 & 163 & 12,97 & 401 \\
\hline Chlamys varia & 88 & 2,13 & 47 & 3,75 & 73 \\
\hline Crassostrea angulata & 5 & 0,12 & 2 & 0,15 & 8 \\
\hline Glycymeris glycymeris & 16 & 0,39 & 14 & 1,11 & 159 \\
\hline Glycymeris sp. & 121 & 2,94 & 69 & 5,49 & 1468 \\
\hline Laevicardium sp. & 1 & 0,02 & 1 & 0,07 & 2 \\
\hline Lutraria lutraria & 1 & 0,02 & 1 & 0,07 & 1 \\
\hline Mytilus sp. & 2 & 0,04 & 2 & 0,15 & 7 \\
\hline Ostrea edulis & 46 & 1,11 & 32 & 2,55 & 1783 \\
\hline Ostrea sp. & 1 & 0,02 & 1 & 0,07 & 8 \\
\hline Pecten maximus & 103 & 2,5 & 38 & 3,02 & 153 \\
\hline Pecten sp. & 15 & 0,36 & 10 & 0,79 & 13 \\
\hline Ruditapes decussatus & 2113 & 51,32 & 167 & 13,29 & 1219 \\
\hline Scrobicularia plana & 2 & 0,04 & 1 & 0,07 & 1 \\
\hline Solen marginatus & 531 & 12,89 & 127 & 10,11 & 200 \\
\hline Veneridae & 3 & 0,07 & 3 & 0,23 & 3 \\
\hline Venus verrucosa & 2 & 0,04 & 2 & 0,15 & 9 \\
\hline Total bivalvos marinos & 3392 & 82,39 & 700 & 55,73 & 5561 \\
\hline GASTERÓPODOS MARINOS & NR & $\%$ NR & NMI & $\%$ NMI & Peso \\
\hline Bolinus brandaris & 17 & 0,41 & 17 & 1,35 & 142 \\
\hline Cerithium vulgatum & 47 & 1,14 & 47 & 3,75 & 107 \\
\hline Columbella rustica & 1 & 0,02 & 1 & 0,07 & 1 \\
\hline Conus mediterraneus & 1 & 0,02 & 1 & 0,07 & 2 \\
\hline Cymatium parthenopeum & 1 & 0,02 & 1 & 0,07 & 4 \\
\hline Cypraeidae & 1 & 0,02 & 1 & 0,07 & 1 \\
\hline Charonia lampas & 19 & 0,46 & 16 & 1,28 & 483 \\
\hline Gasterópodo indeterminado & 2 & 0,04 & 2 & 0,15 & 5 \\
\hline Hexaplex trunculus & 247 & 5,99 & 155 & 12,34 & 1253 \\
\hline Muricidae & 1 & 0,02 & 1 & 0,07 & 1 \\
\hline Nassarius reticulatus & 11 & 0,26 & 11 & 0,87 & 14 \\
\hline Ocenebra erinacea & 2 & 0,04 & 2 & 0,15 & 3 \\
\hline Osilinus lineatus & 320 & 7,77 & 250 & 19,9 & 1503 \\
\hline Osilinus sp. & 4 & 0,09 & 2 & 0,15 & 3 \\
\hline Osilinus turbinata & 5 & 0,12 & 5 & 0,39 & 22 \\
\hline Patella rustica & 1 & 0,02 & 1 & 0,07 & 3 \\
\hline Patella sp. & 8 & 0,19 & 7 & 0,55 & 20 \\
\hline Patella ulyssiponensis & 1 & 0,02 & 1 & 0,07 & 2 \\
\hline Siphonaria pectinata & 3 & 0,07 & 3 & 0,23 & 5 \\
\hline Stramonita haemastoma & 7 & 0,17 & 5 & 0,39 & 13 \\
\hline Zonaria pyrum & 5 & 0,12 & 5 & 0,39 & 14 \\
\hline Total gasterópodos & 704 & 17,09 & 534 & 42,51 & 3601 \\
\hline Crustáceos & NR & $\%$ NR & NMI & $\%$ NMI & Peso \\
\hline Balanus sp. & 16 & 0,39 & 16 & 1,28 & 120 \\
\hline Brachyura sp. & 3 & 0,07 & 3 & 0,23 & 8 \\
\hline Total crustáceos & 19 & 0,46 & 19 & 1,51 & 128 \\
\hline CEFalópodos & NR & $\% \mathrm{NR}$ & NMI & $\%$ NMI & Peso \\
\hline Sepia sp. & 1 & 0,02 & 1 & 0,07 & 2 \\
\hline Total cefalópodo & 1 & 0,02 & 1 & 0,07 & 2 \\
\hline CNIDARIOS & NR & $\% \mathrm{NR}$ & NMI & $\%$ NMI & Peso \\
\hline Coral & 2 & 0,04 & 2 & 0,15 & 3 \\
\hline Total cnidarios & 2 & 0,04 & 2 & 0,15 & 3 \\
\hline TOTAL & 4118 & 100 & 1256 & 100 & 9295 \\
\hline
\end{tabular}

et al., 2010). En este sentido, se ha efectuado un análisis sobre el conjunto malacológico que ha proporcionado la documentación de 4118 restos pertenecientes a un número mínimo de 1256 individuos (Fig. 4). La variabilidad taxonómica viene determinada por el registro de los bivalvos Ruditapes decussatus (13,29\% del número mínimo de individuos -en adelante NMI-), Chlamys sp. (12,97\% del NMI), Solen marginatus (10,11\% del NMI) $\mathrm{y}$ con unos valores más bajos Glycymeris sp. (5,49\% del NMI), Chlamys varia $(3,75 \%$ del NMI) y Pecten maximus (3,02\% del NMI). Especies como Barbatia barbata, Laevicardium sp., Lutraria lutraria o Scrobicularia plana han sido descritas a partir de un registro mínimo $(0,07 \%$ del $\mathrm{NMI})$, por lo que su documentación en el yacimiento se considera como meramente accidental. En cuanto a los gasterópodos, se han identificado Osilinus lineatus (19,90\% del NMI), Hexaplex trunculus $(12,34 \%$ del NMI), Cerithium vulgatum $(3,75 \%$ del NMI), Bolinus brandaris (1,35\% del NMI) y Charonia lampas (1,28\% del NMI). El resto de especies registradas poseen unos índices de abundancia especialmente bajos para considerarlos como pertenecientes a una recolección intencionada (por debajo del $1 \%$ del NMI). En otro orden, en esta fase de Campo de Hockey también ha sido posible la documentación de dos especies de crustáceos. Por un lado, se ha detectado presencia de Balanus sp. (1,28\% del NMI) y restos de dactilopodio del orden Brachyura (0,23\% del NMI), además del cefalópodo Sepia sp. (0,07\%).

FIG. 4. Representatividad taxonómica en Campo de Hockey. 


\subsection{El yacimiento arqueológico de SET Parralejos y los recursos malacológicos}

El asentamiento SET Parralejos se localiza en un cerro del término municipal de Vejer de la Frontera (Cádiz), a unos 182 m.s.n.m. Domina una amplia zona de la antigua laguna de La Janda, ahora desecada, y conecta visualmente con otros espacios naturales que quedan delimitados por las cuencas del río Barbate y el río Salado, así como por la franja litoral que se traza entre los términos municipales de Vejer de la Frontera y Conil de la Frontera. En la actualidad la distancia del yacimiento a la costa se ha calculado en $9,5 \mathrm{~km}$ en línea recta. El hallazgo del sitio arqueológico se produjo en 2008 durante los trabajos de control de movimiento de tierras de la subestación eléctrica Parralejos. El yacimiento se adscribe a los denominados campos de silos (Fig. 5). Se documentaron 59 de estas estructuras, tres zanjas y un área definida como huellas de poste. La excavación se efectuó en todas las unidades estructurales, sobre unos 3000 $\mathrm{m}^{2}$, exceptuando 25 silos que quedaron en reserva por orden de la Consejería de Cultura de la Junta de Andalucía ${ }^{8}$. La estratigrafía vertical del yacimiento era bastante sencilla. En el área intervenida se documentó un primer nivel de tierra parda forestal, con vocación para el cultivo de cereal, en el que las actuaciones previas de prospección superficial no

${ }^{8}$ Villalpando, A. y Montañés, M.: "El yacimiento de SET Parralejos, Vejer de la Frontera (Cádiz). Un núcleo de población de la Prehistoria Reciente en las estribaciones del río Salado de Conil de la Frontera". En Ramos, J.; Cantillo, J. J. y Vijande, E. (coords.): Las ocupaciones prehistóricas y la Arqueología de Conil en el contexto de la Banda Atlántica de Cádiz. Conil de la Frontera, en prensa. detectaron ningún elemento que indicara la existencia de restos arqueológicos. Sin embargo, una vez se retiraron entre 0,30-0,40 m de esta unidad estratigráfica los espacios identificados como silos se hicieron visibles. Estas estructuras negativas se presentaban agrupadas en un número variable y tipología diversa, dominando los de tendencia cilíndrica, seguidos del acampanado, el tipo "pozo" e incluso los falsos silos. El contenido de los mismos no presentaba demasiadas unidades estratigráficas, siendo relativamente abundantes los que contenían un vertido de amortización monofásico. Aquellos que se presentaban con

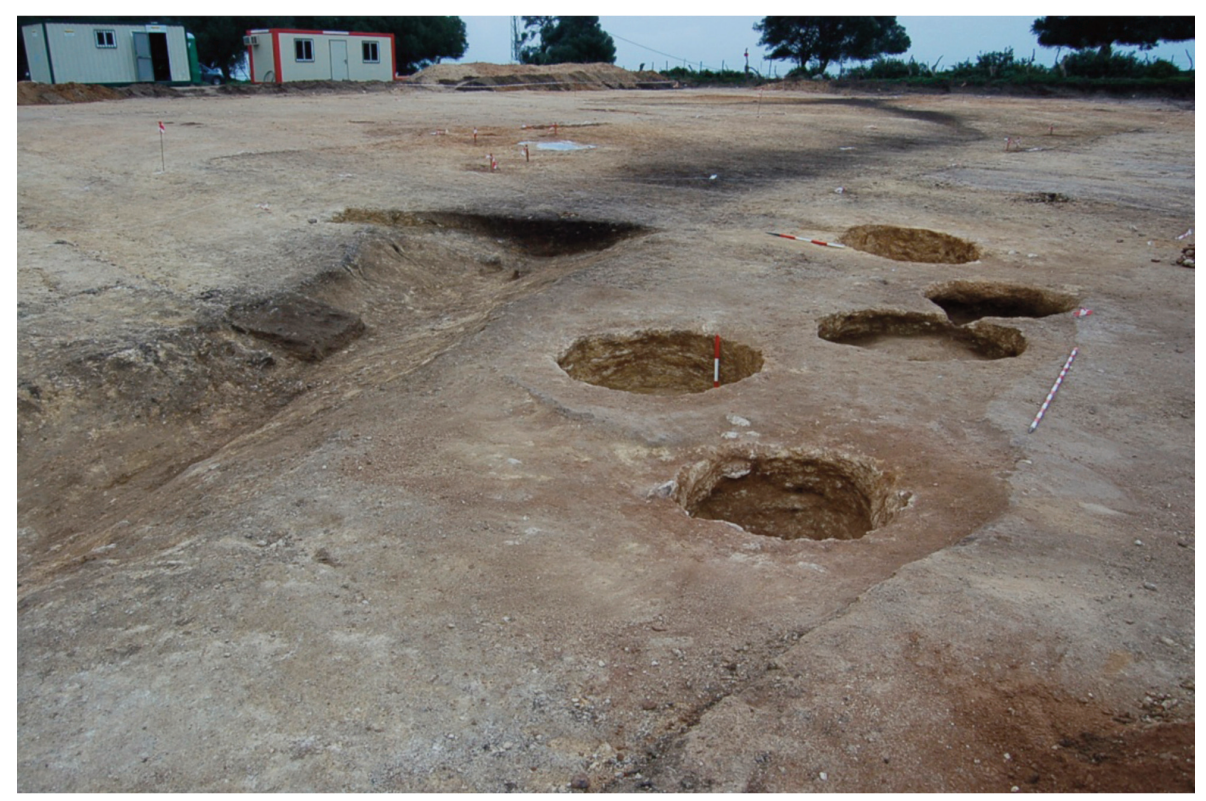

FIG. 5. Vista parcial del yacimiento de SET Parralejos.

dos o tres estratos se correspondían con unidades de nivelación o con diferentes vertidos. La complejidad diacrónica de todo el enclave de Parralejos se entenderá cuando la investigación arqueológica amplíe el área intervenida, ya que los resultados presentados responden a una superficie de ocupación muy reducida, y puede que marginal, respecto al total explotado. Esto quizás explique la homogeneidad cronológica de las cuatro dataciones de $\mathrm{C}^{14}$ analizadas, que oscilan entre 3522 y 3014 cal BC (Fig. 3).

Las formas cerámicas documentadas en Parralejos han sido muy homogéneas y propias de contextos del IV milenio a. C., con cuencos variados, de casquete esférico, semiesférico, escudillas, típicas 


\begin{tabular}{|l|c|c|c|c|c|}
\hline \multicolumn{1}{|c|}{ Taxones } & \multicolumn{5}{c|}{ SET Parralejos } \\
\hline BIVALVos MARINOs & NR & \%NR & NMI & D & Peso \\
\hline Callista chione & 55 & 3,89 & 23 & 11,33 & 304 \\
\hline Cerastoderma edule & 2 & 0,14 & 2 & 0,98 & 2 \\
\hline Chlamys sp. & 25 & 1,76 & 13 & 6,4 & 24 \\
\hline Chlamys varia & 7 & 0,49 & 2 & 0,98 & 18 \\
\hline Glycymeris sp. & 1 & 0,07 & 1 & 0,49 & 5 \\
\hline Panopea glycimeris & 1 & 0,07 & 1 & 0,49 & 25 \\
\hline Pecten maximus & 25 & 1,76 & 11 & 5,41 & 42 \\
\hline Solen marginatus & 34 & 2,4 & 9 & 4,43 & 7 \\
\hline Ruditapes decussatus & 1248 & 88,32 & 127 & 62,56 & 939 \\
\hline Veneridae & 3 & 0,21 & 2 & 0,98 & 12 \\
\hline Venus verrucosa & 1 & 0,07 & 1 & 0,49 & 3 \\
\hline Total bivalvos & 1402 & 99,22 & 194 & 95,56 & 1381 \\
\hline GASTERóPODOs MARINOS & $\mathbf{N R}$ & $\mathbf{9 N R}$ & $\mathbf{N M I}$ & $\mathbf{D}$ & Peso \\
\hline Cymbula nigra & 1 & 0,07 & 1 & 0,49 & 47 \\
\hline Hexaplex trunculus & 2 & 0,14 & 1 & 0,49 & 14 \\
\hline Patella sp. & 3 & 0,21 & 3 & 1,47 & 33 \\
\hline Patella ulyssiponensis & 2 & 0,14 & 2 & 0,98 & 3 \\
\hline Stramonita haemastoma & 1 & 0,07 & 1 & 0,49 & 17 \\
\hline Zonaria pyrum & 2 & 0,14 & 1 & 0,49 & 5 \\
\hline Total gasterópodos & 11 & 0,77 & 9 & 4,43 & 119 \\
\hline TOTAL & $\mathbf{1 4 1 3}$ & $\mathbf{1 0 0}$ & $\mathbf{2 0 3}$ & $\mathbf{1 0 0}$ & $\mathbf{1 5 0 0}$ \\
\hline
\end{tabular}

geométricos y triángulos y proyectiles pedunculados mediante escotaduras en la base con retoque abrupto lateral, así como una interesante producción de pulimentos en ofita.

En relación al conjunto de fauna marina documentada (Cantillo et al., 2010), cabe destacar un registro compuesto por 1403 restos pertenecientes a un número mínimo de 203 individuos (Fig. 6), con un mayor predominio de especies bivalvas, entre las que cabe distinguir Ruditapes decussatus (62,56\% del NMI), Callista chione $(11,33 \%$ del NMI), Chlamys sp. (6,40\% del NMI), Pecten maximus $(5,41 \%$ del NMI) y Solen marginatus ( $4,43 \%$ del NMI), mientras que entre los gasterópodos sólo Patella sp. superaba el 1\% del NMI. Entre este material, al menos en un ejemplar de Zonaria pyrum observamos una clara manipulación antró-

FIG. 6. Representatividad taxonómica en SET Parralejos. pica por abrasión con el objeto de ser usado como adorno.

para el consumo. También han sido documentadas ollas de paredes entrantes y de perfiles oblongos y globulares, de producción para el consumo, con una ausencia casi total de decoración. Los asideros más abundantes fueron mamelones colocados en el cuello del vaso, aunque también se documentaron asas horizontales. La industria lítica tallada se caracterizó por la presencia mayoritaria de industria laminar. Éstas parecen haber sido usadas directamente como elementos enmangados para hoces y cuchillos, aunque debemos esperar a los resultados de las analíticas de funcionalidad para ratificar esta propuesta exegética. También han estado presentes productos como los perforadores, escotaduras, denticulados, laminas de dorso y los buriles, y en menor medida útiles sobre lasca, así como diferentes elementos retardatarios en la tipología lítica, de tradición solutrense, que se fundamentan en la presencia de elementos de talla bifacial con retoque plano invasivo, que supera en repetidas ocasiones la arista central, y configura un producto de talla específico, la punta de aletas y pedúnculo. Junto a todo ello destaca la presencia de

\section{Análisis funcional sobre los moluscos de Campo de Hockey y SET Parralejos}

\subsection{Material y método}

Se han analizado 351 conchas y fragmentos de concha procedentes de Campo de Hockey. Concretamente 307 fragmentos y 5 conchas completas de Ruditapes decussatus, 3 fragmentos y 5 conchas completas de Chlamys sp., 2 conchas completas de Ostrea edulis, 8 completas y 18 fragmentos de Glycymeris sp., 2 fragmentos de Pecten maximus, 1 fragmento de Patella sp., 1 concha completa de Patella rustica y 1 concha completa de Crassostrea angulata (Fig. 7). Teniendo en cuenta que durante la intervención arqueológica se recuperaron 4177 restos de malacofauna marina ha sido analizado el $8,52 \%$ del material malacológico presente en el yacimiento.

En el caso de SET Parralejos se han analizado 287 conchas o fragmentos de concha. Concretamente 237 fragmentos y 39 conchas completas de Ruditapes decussatus, 1 fragmento de Chlamys sp., 3 fragmentos 


\begin{tabular}{|c|c|}
\hline Taxones identificados & $\begin{array}{c}\text { Fragmentos y conchas } \\
\text { completas analizadas }\end{array}$ \\
\hline Ruditapes decussatus & 312 \\
\hline Glycymeris $\mathrm{sp}$. & 26 \\
\hline Chlamys $\mathrm{sp}$. & 8 \\
\hline Ostrea edulis & 2 \\
\hline Pecten maximus & 2 \\
\hline Patella sp. & 1 \\
\hline Patella rustica & 1 \\
\hline Crassostrea angulata & 1 \\
\hline
\end{tabular}

FIG. 7. Taxones y número de restos analizados procedentes de Campo de Hockey.

de Pecten maximus, 1 completa de Pecten sp., 1 fragmento de Cerastoderma edule, 1 completa y 2 fragmentos de Callista chione, 1 concha completa de Venus verrucosa, 1 de Cymbula nigra y 1 de Patella ulyssiponensis (Fig. 8). Durante la intervención realizada en este contexto se recuperaron un total de 1403 restos malacológicos, por lo que la muestra analizada corresponde al 20,45\% del material malacológico presente en el yacimiento.

\begin{tabular}{|c|c|}
\hline Taxones identificados & $\begin{array}{c}\text { Fragmentos y conchas } \\
\text { completas analizadas }\end{array}$ \\
\hline Ruditapes decussatus & 276 \\
\hline Pecten maximus & 3 \\
\hline Callista chione & 3 \\
\hline Pecten sp. & 1 \\
\hline Patella nigra & 1 \\
\hline Patella ulyssiponensis & 1 \\
\hline Chlamys sp. & 1 \\
\hline Venus verrucosa & 1 \\
\hline Cerastoderma edule & 1 \\
\hline
\end{tabular}

FIG. 8. Taxones y número de restos analizados procedentes de SET Parralejos.

Este material ha sido estudiado empleando metodología de análisis funcional (Semenov, 1964), es decir, realizando una observación macroscópica y microscópica para documentar las alteraciones generadas por la utilización instrumental de estas conchas y la experimentación

\begin{tabular}{|c|c|c|c|c|c|}
\hline Localización & Especie & Zona Activa & Uso & Acción & Materia \\
\hline C9a/UE 908 & Ruditapes decussatus & Borde & Uso & TR & Piel? \\
\hline Fc4-Fc5 & Ruditapes decussatus & Borde & Uso & TR & Piel? \\
\hline E5-C5/Ue 500 & Ruditapes decussatus & Borde & Po & TR & $?$ \\
\hline
\end{tabular}

FIG. 9. Instrumentos de concha documentados en Campo de Hockey ( $P O=$ uso posible; $A T=$ acción transversal; $A L=$ acción longitudinal). analítica (González e Ibáñez, 1994) para verificar o refutar la interpretación de estos estigmas. Para realizar dicho análisis se ha empleado una lupa binocular Leica S8APO en busca de brillos, abrasiones, redondeamientos y melladuras. Además se ha empleado un microscopio metalográfico Leica DM2500 para identificar los microrrastros de uso y determinar, cuando ha sido posible, cómo -movimiento y/o acción-y para qué - materia procesada- fueron empleados estos instrumentos. Para la documentación de estas alteraciones de uso se ha empleado una cámara Leica DFC adaptada a ambos equipos. Como modelos comparativos se han utilizado colecciones experimentales desarrolladas en los últimos años (Cuenca 2009, 2010, 2013; Cuenca et al., 2010). Todas estas experimentaciones analíticas se han realizado a partir del control de las variables que intervienen en la formación de las huellas de uso (González e Ibáñez, 1994). El estado de conservación de las piezas analizadas es bastante heterogéneo, en algunos casos la superficie de las conchas se ha visto afectada por diferentes grados de biodegradación y/o de encostramiento, lo que ha dificultado o impedido el correcto análisis funcional, por el contrario, en otros casos ha sido posible realizar un correcto análisis.

\subsection{Resultados}

El análisis funcional de 641 fragmentos y conchas completas sumando los restos de ambos yacimientos ha permitido documentar diez conchas o fragmentos con huellas de uso. Concretamente en el contexto de Campo de Hockey tres fragmentos de borde de Ruditapes decussatus, dos de ellas con un uso seguro y otro más con uso posible (Po) (Fig. 9).

El fragmento C9a/UE 908 presenta un pulido bastante desarrollado, de trama cerrada, con microtopografía irregular y estrías perpendiculares y oblicuas muy finas y de fondo oscuro. Se evidencian 


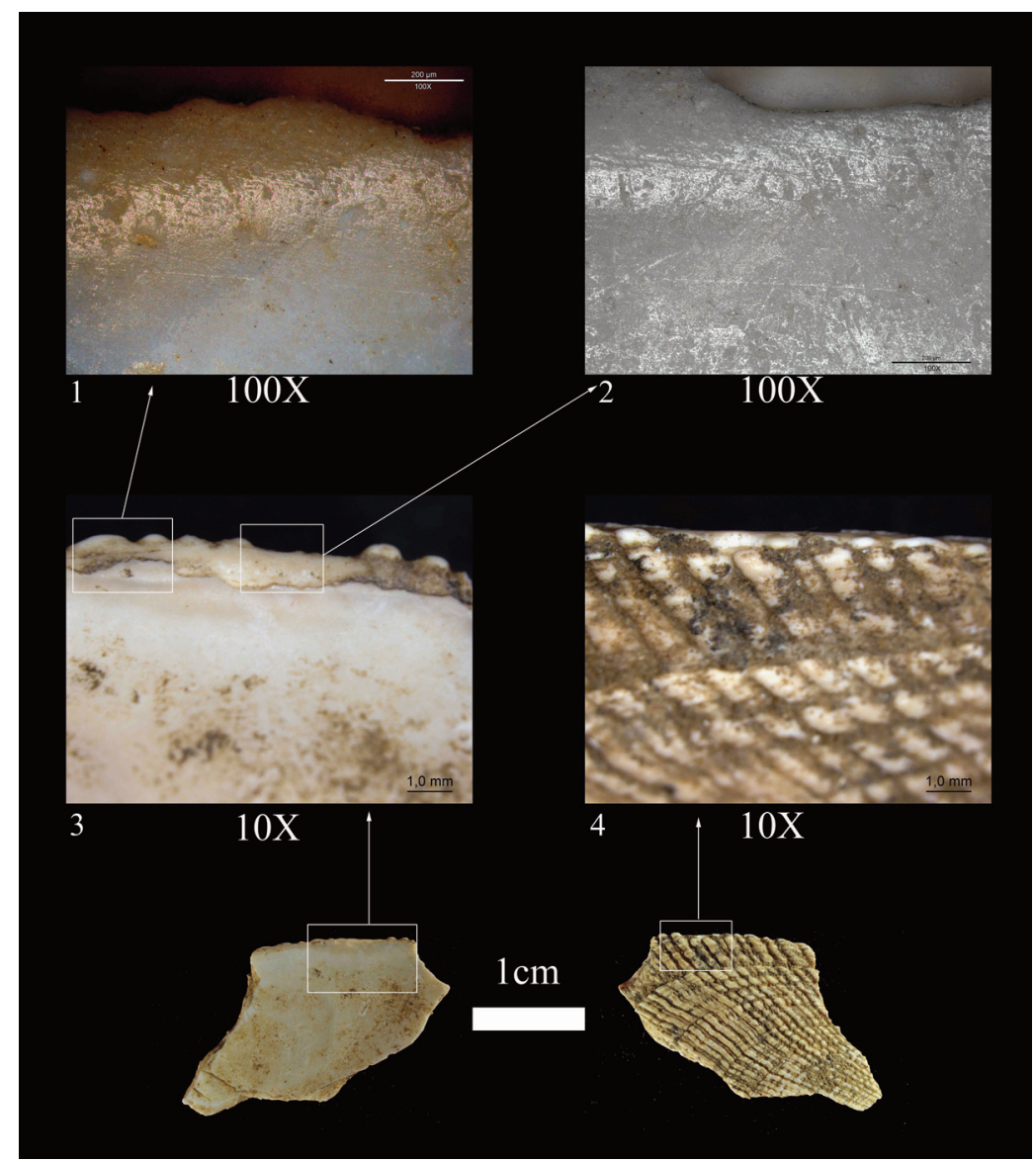

FIG. 10. Fragmento de Ruditapes decussatus Fc4-Fc5 de Campo de Hockey, probablemente vinculado al procesado de piel.

algunos microagujeros de morfología predominantemente circular. El borde de la concha en esta zona activa presenta algunas micromelladuras aisladas de morfología semicircular, así como un redondeamiento de grado medio en el borde que ha funcionado como zona activa. Según la orientación de las estrías y la disposición lineal del pulido las huellas de uso son resultado de haber realizado con el instrumento una acción transversal probablemente de raspado. Sobre la cara externa apenas se aprecia alteración ni a nivel macroscópico ni a nivel microscópico, por lo que no parece que haya existido contacto de esta zona de la concha con la materia procesada, o éste ha sido muy leve o insuficiente para alterarla. Teniendo en cuenta estas características, las huellas podrían ser el resultado de procesar una materia de dureza media y abrasiva, quizás piel, pero no demasiado seca ya que habría generado mayor cantidad de estrías y surcos sobre la superficie activa (Cuenca Solana et al., 2010).

El fragmento Fc4-Fc5 (Fig. 10) presenta un pulido de trama cerrada con microtopografía irregular y estrías perpendiculares y oblicuas, finas y de fondo oscuro (Fig. 10, n. ${ }^{\circ}$ 1 ), junto a algunos microagujeros de morfología predominantemente circular (Fig. 10, n. ${ }^{\circ}$ 2). El borde de la concha en la zona activa presenta algunas micromelladuras aisladas $y$ un redondeamiento de grado medio (Fig. 10, n. ${ }^{o}$ 3). Según la orientación de las estrías y la disposición lineal del pulido se habría realizado una acción transversal, probablemente para llevar a cabo una actividad de raspado, siendo en este caso la cara interna la conductora durante el movimiento. Sobre la cara externa se documenta alteración a nivel macroscópico, por lo que ha existido contacto de esta zona de la concha con la materia, un contacto que ha eliminado en zonas puntuales del borde de la cara externa la capa superficial. Las huellas podrían ser el resultado de procesar una materia de dureza media y abrasiva como la piel.

El fragmento E5-C5/Ue 500 (Fig. 11) presenta un pulido cerrado de microtopografía rugosa y aspecto brillante, localizado marginalmente en el borde de la concha (Fig. 11, n. ${ }^{\text {os }} 1$ y 2). Esta zona presenta un redondeamiento de grado medio-bajo (Fig. 11, n. ${ }^{\circ}$ 3). La disposición lineal del pulido parece mostrar la ejecución de una acción transversal -TR- de raspado. Se trata de un uso posible (Po) que debido al escaso desarrollo de las huellas de uso no puede confirmarse con certeza. Por este motivo tampoco ha sido posible establecer una hipótesis suficientemente definitoria sobre la materia trabajada, aunque podría tratarse de una materia blanda y no demasiado abrasiva. Probablemente procesada durante un intervalo de tiempo corto, o al menos 
insuficiente para desarrollar más los rastros.

El análisis de la muestra analizada en SET Parralejos ha proporcionado siete fragmentos o conchas completas de Ruditapes decussatus con uso o uso posible (Fig. 12). Concretamente se trata de una valva derecha completa con uso posible (1019C), cuatro fragmentos con uso posible, uno de valva derecha (1019A) y dos de valvas izquierdas (1019B y 1021), un fragmento de valva derecha retocado para manufacturar un denticulado con uso posible (1052C) y tres fragmentos más de valva izquierda con uso (1019B, 1052A y 1052B).

El fragmento de valva derecha 1019A presenta un escaso desarrollo del pulido; sin embargo, se aprecia un redondeamiento de grado medio en el borde y numerosas estrías de fondo oscuro orientadas en perpendicular y en oblicuo. La orientación de estos rastros podría indicar el desarrollo de una acción transversal intercalando algún movimiento longitudinal, aunque la

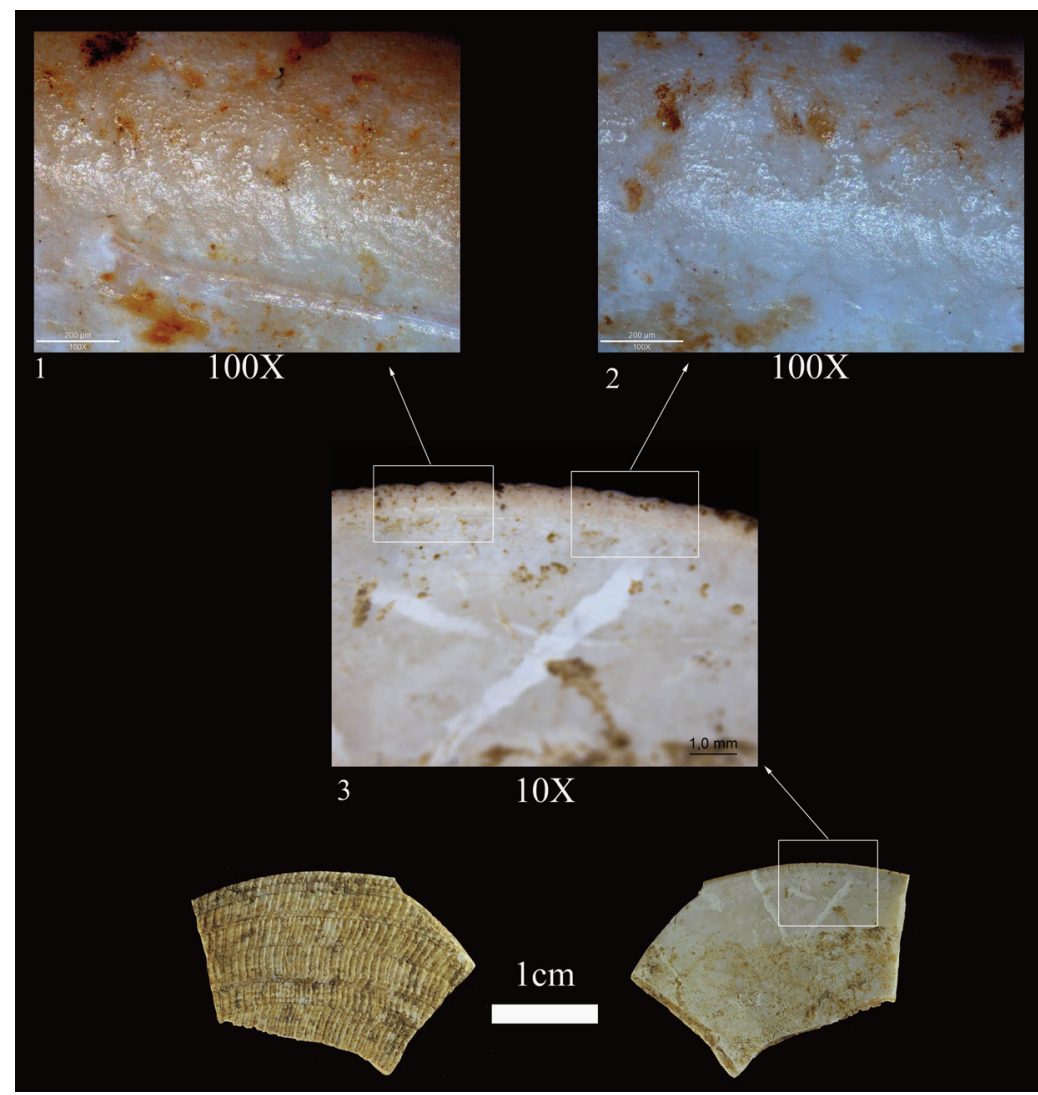

FIG. 11. Fragmento de Ruditapes decussatus E5-C5/Ue 500 de Campo de Hockey. ausencia de rastros en la cara externa impide definir si se trata de una acción unidireccional o bidireccional. El escaso desarrollo del pulido no permite confirmar con certeza el uso de esta pieza, de ahí su definición como uso posible, sin poder tampoco establecer ninguna hipótesis acerca de la materia procesada.

El fragmento de valva izquierda 1019B (Fig. 13) presenta un mayor desarrollo del pulido, junto a un redondeamiento de grado medio en el borde (Fig. 13, n. ${ }^{\circ}$ 3) y numerosas estrías de fondo oscuro orientadas en longitudinal y en oblicuo (Fig. 13, n. ${ }^{\text {os } 1-2) . ~ L a ~ o r i e n t a c i o ́ n ~ d e ~}$ estos rastros podría indicar el desarrollo de una acción longitudinal. Sin embargo, no ha sido posible establecer ninguna hipótesis acerca de la materia procesada.

La valva derecha completa de Ruditapes decussatus 1019C presenta

\begin{tabular}{|c|c|c|c|c|c|}
\hline Localización & Especie & Zona Activa & Uso & Acción & Materia \\
\hline 1019A & Ruditapes decussatus & Borde & Po & TR & $?$ \\
\hline 1019B & Ruditapes decussatus & Borde & Po & TR & $?$ \\
\hline 1019C & Ruditapes decussatus & Borde & Po & TR & $?$ \\
\hline 1021 & Ruditapes decussatus & Borde & Po & TR & $?$ \\
\hline 1052A & Ruditapes decussatus & Borde & Uso & TR & Fibras vegetales \\
\hline 1052B & Ruditapes decussatus & Borde & Po & TR & $?$ \\
\hline 1052C & Ruditapes decussatus & Borde & Po & $?$ & $?$ \\
\hline
\end{tabular}

FIG. 12. Instrumentos con huellas de uso documentados en SET Parralejos ( $P O=$ uso posible; $A T=$ acción transversal; $A L=$ acción longitudinal; $A T / A L=$ acción transversal y longitudinal intercaladas). 


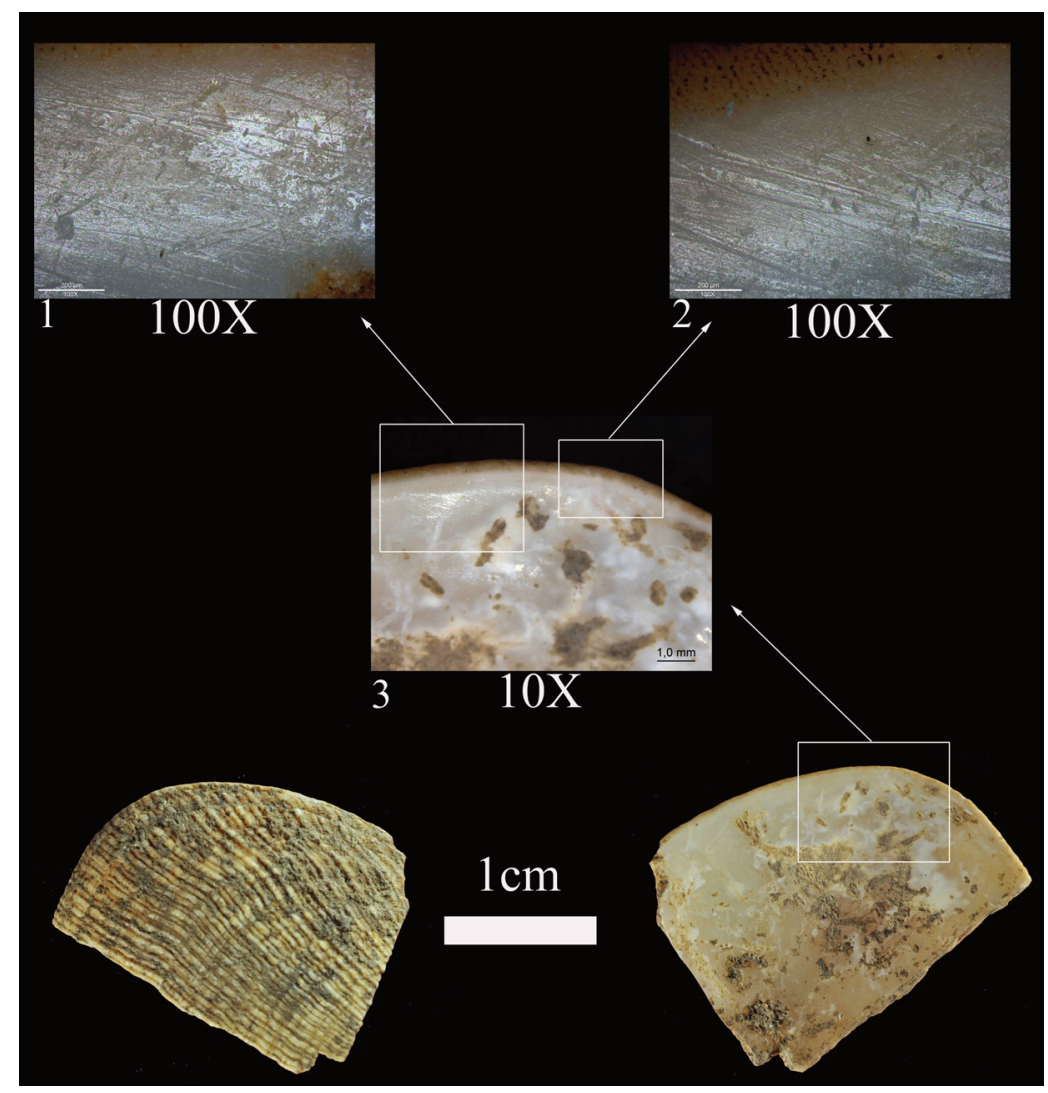

FIG. 13. Fragmento de Ruditapes decussatus 1019B con huellas de uso documentado en SET Parralejos.

longitudinal, más largas y de fondo brillante, probablemente relacionadas con alguna alteración posdeposicional. Debido al escaso desarrollo del pulido es difícil confirmar de forma segura el uso así como la materia procesada, por lo que establecemos que se trata de un uso posible.

El fragmento de valva izquierda 1021 presenta escaso desarrollo del pulido y un redondeamiento de grado medio en el borde con algunas micromelladuras aisladas e irregulares. También se han documentado numerosas estrías de fondo oscuro, orientadas en perpendicular y en paralelo al borde, y en menor medida también en oblicuo. La orientación de estos rastros podría indicar el desarrollo de una acción transversal intercalando acciones longitudinales, aunque la ausencia de rastros en la cara externa impide definir si se trata de una acción unidireccional o bidireccional. Debido al escaso desarrollo del pulido no es posible confirmar el uso de esta pieza, ni tampoco establecer ninguna hipótesis acerca de la materia procesada.

El fragmento de valva izquierda 1052A presenta un redondeamiento de grado medio-bajo en el borde (Fig. 14, n. ${ }^{\circ}$ 3). Además en la cara interna de la concha se ha documentado un pulido de trama cerrada y microtopografía irregular, junto a estrías muy numerosas, largas, anchas e irregulares, localizadas principalmente en perpendicular al borde (Fig. 14, n. ${ }^{\circ}$ 2). Algunas zonas localizadas en el interior de la cara interna muestran una disposición más caótica de las estrías (Fig. 14, n. $\left.{ }^{\circ} 1\right)$. La orientación de éstas y la disposición lineal del pulido indican la realización de una acción transversal de raspado. La materia procesada es abrasiva pero dúctil, tanto que ha penetrado muy al interior de la zona activa del instrumento de trabajo. Estas alteraciones se han desarrollado en la cara interna de la concha, que ha ejercido de conductora durante el desarrollo de la acción. Sin embargo, no se han documentado alteraciones en la cara externa. Debido a estas características consideramos que la materia procesada podría ser un vegetal no leñoso, quizás para obtener fibras abriendo y estirando la planta mediante raspado.

El fragmento de valva izquierda 1052B presenta un redondeamiento de grado bajo en el borde, junto a un pulido de trama semicerrada y microtopografía irregular. Destaca la presencia de surcos muy numerosos, cortos, anchos, irregulares y de fondo oscuro, localizados principalmente en perpendicular. La disposición lineal del pulido y la orientación de los surcos indican la realización de una acción transversal. Debido al escaso desarrollo de estas huellas es complejo determinar la materia procesada.

El fragmento de valva derecha 1052C (Fig. 15) ha sido retocado para manufacturar un filo denticulado sobre el borde natural de la concha. Las zonas retocadas presentan un redondeamiento de grado medio (Fig. 15, n. ${ }^{\text {os }} 3-4$ ). En esta zona activa se ha 
desarrollado un pulido semicerrado de microtopografía rugosa, junto a alguna estría muy fina de fondo oscuro orientada en perpendicular al borde (Fig. 15, n. ${ }^{\circ}$ 1). En todo caso el desarrollo de estas alteraciones de uso es leve, por lo que es difícil, a pesar de tratarse de una pieza formatizada (Binford, 1998), confirmar su uso y aún más aportar alguna hipótesis acerca de la materia procesada y la acción desarrollada con este instrumento de trabajo. En este sentido, la aparición de zonas de concreción en la zona activa contribuye también a dificultar el análisis de esta pieza (Fig. 15, n. ${ }^{\circ}$ 2). Se trata por ello de una pieza retocada con un uso posible.

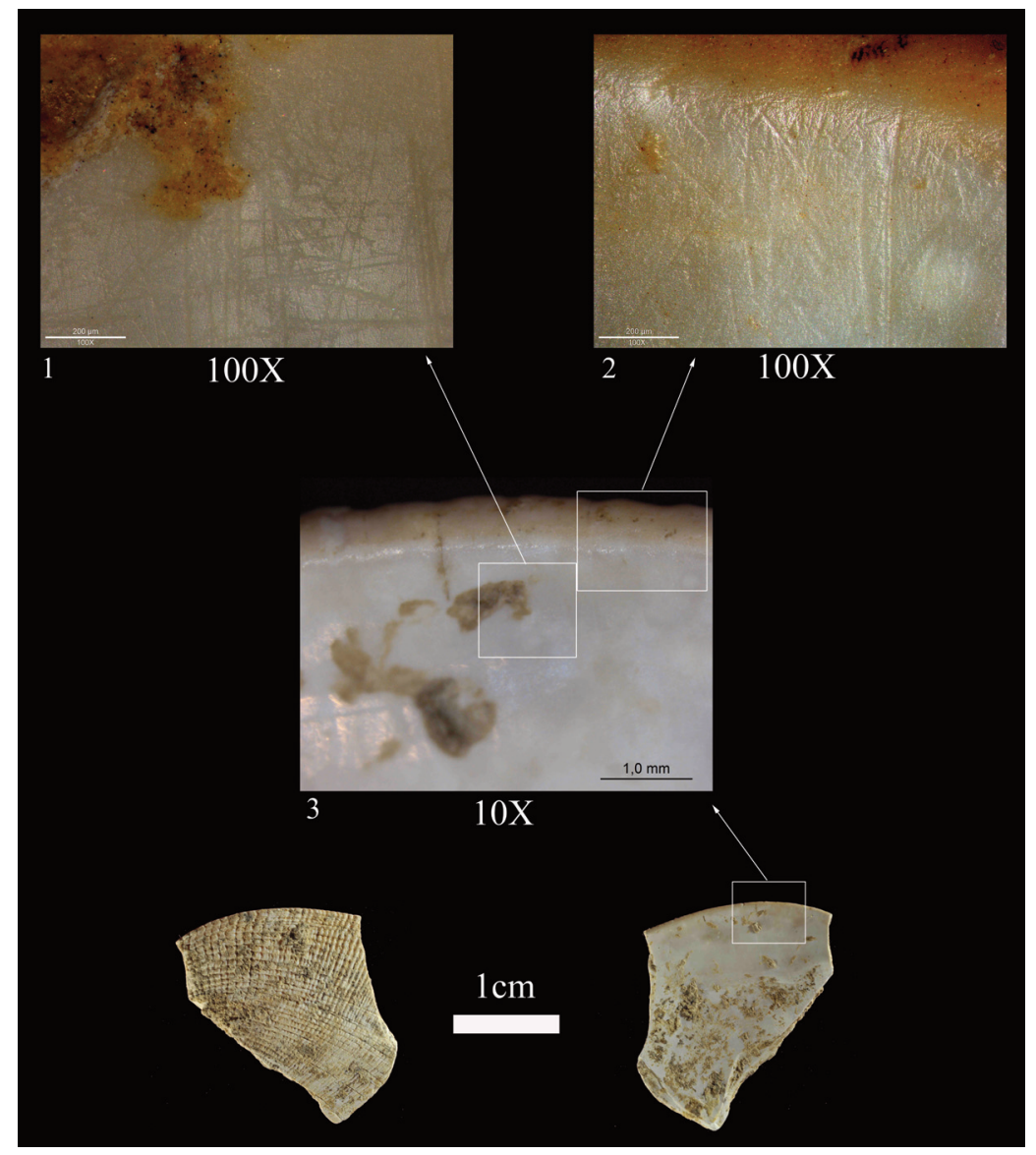

FIG. 14. Fragmento de Ruditapes decussatus 1052A con huellas de uso documentado en SET Parralejos. presentes en las conchas recuperadas en SET Parralejos y Campo de Hockey ha sido posible reconocer el desarrollo de diferentes actividades con estos instrumentos. De esta forma, probablemente se habrían llevado a cabo actividades transversales de raspado para procesar piel -fragmentos C9a/UE 908 y Fc4-Fc5 en Campo de Hockey- y fibras vegetales -fragmento 1052A en SET Parralejos-. El uso de conchas para realizar estas actividades ya había sido documentado anteriormente en otros contextos neolíticos como Santimamiñe (Gutiérrez Zugasti et al., 2011) o La Draga (Clemente y Cuenca, 2011). A nivel experimental las conchas se han mostrado muy efectivas para realizar actividades de raspado -tanto unidireccional como bidireccional- para manufacturar o procesar este tipo de materias blandas o de

$$
{ }^{9} \text { Cf. n. } 1 .
$$

dureza media (Cuenca, 2013; Cuenca et al., 2010). Además la información etnográfica también nos muestra una gama de variados ejemplos en diferentes horizontes geográficos acerca de la utilización instrumental de las conchas para procesar materias blandas y de dureza media, tanto en acciones transversales de raspado como longitudinales empleando fragmentos obtenidos mediante percusión para realizar actividades de corte (Cuenca et al., 2011).

El resto de fragmentos documentados, a pesar de no haber sido posible establecer de forma concreta la materia procesada, ha podido vincularse al desarrollo de actividades de cinemática transversal orientadas a procesar materias blandas o de dureza media en trabajos de corta duración. La realización de un programa experimental específicamente vinculado al 


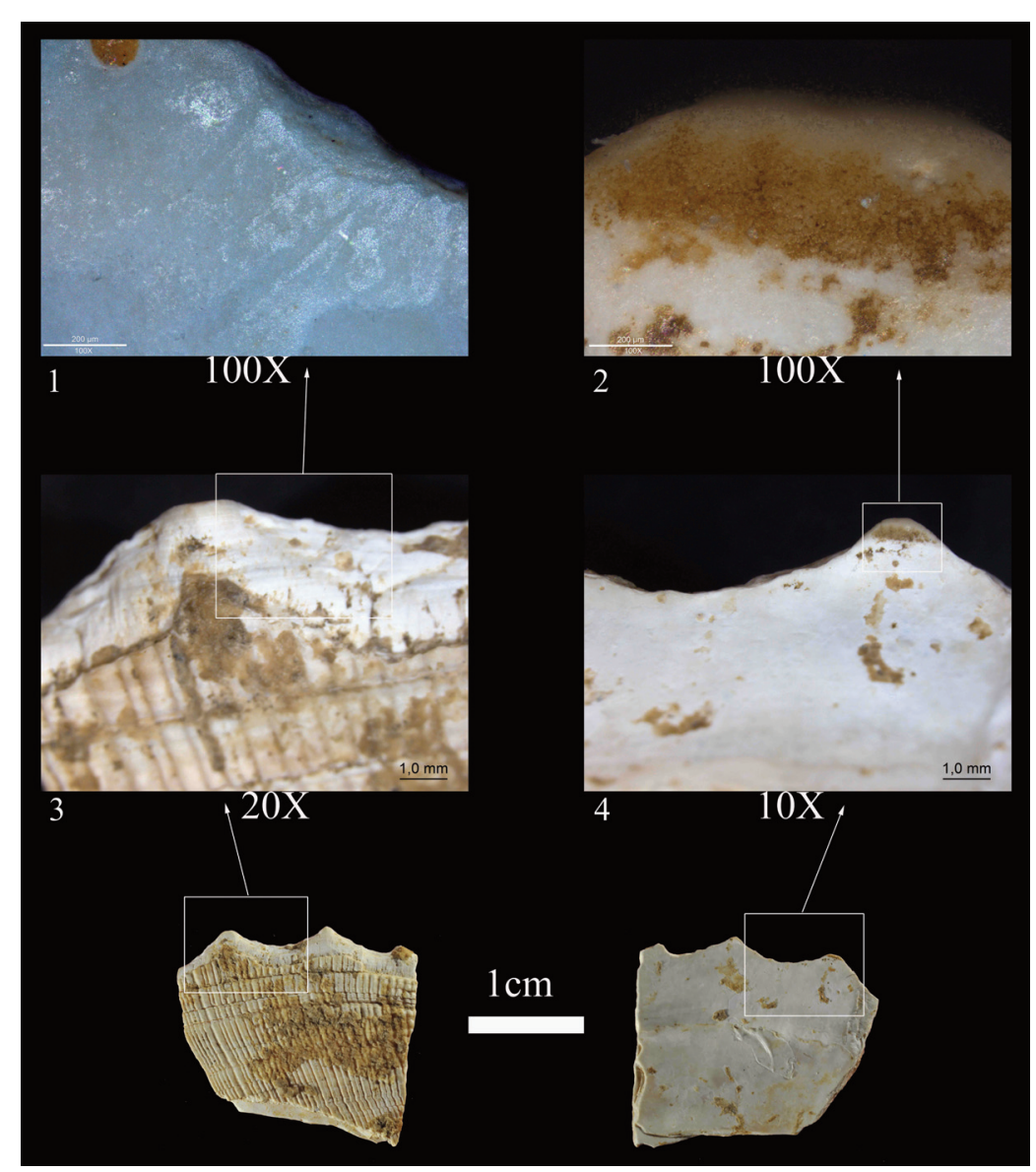

FIG. 15. Fragmento de Ruditapes decussatus 1052C de SET Parralejos retocado para manufacturar un denticulado.

conocimiento de las alteraciones tafonómicas (Cuenca Solana, 2013) y también de aquellas producidas por el trabajo arqueológico (Cuenca Solana, 2010), junto a la propia coherencia de los rastros de uso analizados, vinculan de forma clara las alteraciones documentadas en estas piezas a un uso instrumental. Descartando de esta forma que la formación de las estrías, pulidos o redondeamientos documentados sobre estas conchas pueda deberse a procesos postdeposicionales o generados durante la propia intervención arqueológica.

Respecto al número de piezas con huellas de uso documentadas en estos yacimientos encontramos que el 2,430\% de las piezas analizadas en SET Parralejos y el 0,849\% en Campo de Hockey presentan huellas de uso. Estos porcentajes, que pueden parecer bajos, tienen que ser matizados por varios aspectos. Es pertinente señalar que el porcentaje de uso más elevado coincide con el análisis de un mayor porcentaje de restos malacológicos respecto al total de los recuperados durante la intervención arqueológica $(20,382 \%$ del total analizado en SET Parralejos). Este dato sugiere que un aumento de la muestra analizada podría significar un ascenso del porcentaje de piezas usadas. Esta cuestión probablemente pueda ser verificada en un futuro al completar el análisis de todo el material malacológico recuperado en sendas intervenciones arqueológicas. Sin embargo, también debe tenerse en cuenta que en los registros donde se han analizado desde el punto de vista funcional conjuntos completos de tecnología lítica (Clemente Conte, 1997; Ramos et al., 2005) el porcentaje de piezas con huellas de uso tampoco se ha mostrado excesivamente alto -el 8\% en el asentamiento Yámana de Tunel VII o el $9 \%$ en el contexto mesolítico del embarcadero del río Palmones-.

La documentación de estas nuevas evidencias, junto al resto de aportaciones que se están realizando últimamente ${ }^{10}$ (Cuenca et al., 2010, 2011; Cuenca, 2013), son una muestra de la diversidad funcional para la que pueden orientarse este tipo de instrumentos de trabajo. Constituyéndose de esta forma como un conjunto instrumental versátil y capaz de procesar recursos de diferente dureza, elasticidad y abrasividad. Además, la captación de algunos de estos recursos malacológicos podría ser muy rentable al permitir varios consumos diferidos - bromatológico, como elemento de adorno e instrumental-, y con ello gran variedad de soluciones para afrontar las necesidades productivas de los grupos humanos prehistóricos. En el caso de los contextos analizados,

$$
{ }^{10} \text { Cf. n. } 1 .
$$


parece probable que la captación inicial de los recursos malacológicos orientados a su consumo directo como alimento pudo ser posteriormente sometida a un nuevo consumo -indirecto-, al ser empleados para desarrollar una función tecnológica en un nuevo proceso productivo. En este sentido, parece que la mayor parte de los instrumentos de concha documentados en el análisis podrían haber funcionado como utillaje expeditivo -salvo la pieza retocada 1052C de SET Parralejos-, ya que no presentan ningún tipo de modificación de sus características naturales para mejorar su funcionalidad. El desarrollo de los rastros de uso, escaso en muchos casos para ser suficientemente característicos de la materia procesada, indica que su utilización probablemente estuvo orientada a desarrollar actividades de corta duración. Este tipo de uso de los instrumentos de concha podría explicarse por varios motivos: tanto por la sustitución del instrumento de trabajo al decaer ligeramente la efectividad funcional, algo fácil en un contexto con varios miles de fragmentos de conchas, o también por su utilización en una tarea aislada y escasamente recurrente durante el desarrollo de una actividad productiva concreta. En este sentido, es posible que el empleo de un instrumental fácilmente sustituible y por tanto de escaso coste por su fácil obtención -en este caso las conchas de Ruditapes decussatuspudiera servir para proteger y conservar el instrumental de mayor valor -lítico y óseo-, utillaje que además exige la realización de actividades de producción de mantenimiento (Castro et al., 1998) para conservar su correcta funcionalidad. De este modo, desde un punto de vista conceptual el utillaje de concha podría encajar en estos contextos dentro del ámbito de los Medios de Producción de estos grupos como instrumento de trabajo o Medio de Trabajo Circulante (Gassiot, 2002). Éstos estarían definidos por su utilización en un solo ciclo productivo, frente a los Medios de Trabajo Fijos (Gassiot, 2002), empleados de forma permanente durante varios ciclos de producción al perdurar su funcionalidad después de obtener el bien buscado. Bajo este esquema, la utilización de instrumentos de concha para el desarrollo de algunas acciones vinculadas a procesos de producción podría suponer un aumento del periodo de amortización de los Medios de Trabajo Fijos -líticos y óseos-, rentabilizando aún más la inversión realizada en éstos -captación de la materia prima, formatización y tareas de mantenimiento-.

En el futuro esperamos que el desarrollo de nuevas analíticas de funcionalidad sobre este tipo de materiales, y también sobre el resto de utillaje recuperado en estos contextos, permita aumentar nuestro conocimiento sobre las formaciones económico-sociales que los emplearon para desarrollar algunas de sus actividades productivas. Para ello será necesario integrar esta información dentro de una visión global de los medios de producción teniendo en cuenta el conjunto de elementos tecnológicos empleados por estas sociedades tribales como medio de producción e instrumento de trabajo.

\section{Bibliografía}

Alonso, C.; Gracia, F. J. y Benavente, J. (2009): "Evolución histórica de la línea de costa en el sector meridional de la Bahía de Cádiz", Revista AtlánticaMediterránea de Prehistoria y Arqueología Social, 11, pp. 13-37.

Arteaga, O.; Schulz, H. y Roos, A. M. a (2008): "Geoarqueología Dialéctica en la Bahía de Cádiz”. En ARTEAGA, O. y Schulz, H. (eds.): Geoarqueología y proceso histórico en la Bahía de Cádiz. Revista Atlántica-Mediterránea de Prehistoria y Arqueología Social, 10, pp. 21-116.

BinforD, L. W. (1998): En busca del pasado. Descifrando el registro arqueológico. Barcelona: edit. Crítica.

Cantillo, J. J.; Ramos, J.; Soriguer, M.; Pérez, M.; Vijande, E.; Bernal, D.; Domínguez-Bella, S.; Zabala, C.; Hernando, J. y Clemente, I. (2010): "La explotación de los recursos marinos por sociedades cazadoras-recolectoras-mariscadoras y tribales comunitarias en la región histórica del Estrecho de Gibraltar”. En GONZÁlez Gómez, E.; BEJEGA, V.; FERnÁNDEZ RodrígueZ, C. y Fuertes, N. (eds.): $I$ Reunión de Arqueomalacología de la Península Ibérica. Férvedes, 6, pp. 105-113.

Castro, P. V.; Gili, S.; Lull, V.; Micó, R.; Rihuete, C.; Risch, R. y Sanahuja, M. ${ }^{a}$ E. (1998): “Teoría de la producción de la vida social. Mecanismos de explotación en el sudeste ibérico", Boletín de Antropologia Americana, 33, pp. 25-27.

Clemente, I. (1997): Los instrumentos líticos de Túnel VII: una aproximación etnoarqueológica. Treball d'etnoarqueología, 2. Barcelona: CSIC-UAB.

Clemente, I. y Cuenca, D. (2011): "Instrumentos de trabajo de concha en el yacimiento Neolítico de La Draga”. En Bosch, A.; Chinchilla, J. y Tarrús, J. 
(eds.): El poblat lacustre del neolitic antic de la Draga. Excavacions 2000-2005. Monografies del CASC, 9. Museu d'Arqueologia de Catalunya. Centre d'Arqueologia Subaquàtica de Catalunya, pp. 106-112.

Cristiani, E.; Lemorini, C.; Martini, F. y Sarti, L. (2005): "Scrappers of Callista chione from Grotta del Cavallo (Middle Paleolithic cave in Apulia): evaluating use-wear potential". En LUIK, H.; CHAYKe, A. M.; BateY, C. E. y Lougos, L. (eds.): From hooves to horns, from mollusc, to mammoth. Manufacture and use of bone artefacts from prehistoric times to the present. Procedings of the 4th meeting of the ICAZ Worked bone Research Group at Tallin, pp. 319-324.

CuencA, D. (2010): "Los efectos del trabajo arqueológico en conchas de Patella sp. y Mytilus galloprovincialis y su incidencia en el análisis funcional”. En GonZález Gómez, E.; Bejega García, V.; FERnÁNdez Rodríguez, C. y Fuertes Prieto, N. (eds.): I Reunión de Arqueomalacología de la Península Ibérica. Férvedes, 6, pp. 43-51.

- (2013): Utilización de instrumentos de concha para la realización de actividades productivas en las formaciones económico-sociales de los cazadores-recolectores-pescadores y primeras sociedades tribales de la fachada atlántica europea. Serie Tesis Doctorales, 4. Santander: Univ. Cantabria.

Cuenca, D.; Clemente, I. y Gutiérrez-Zugasti, I. (2010): "Utilización de instrumentos de concha durante el Mesolítico y Neolítico inicial en contextos litorales de la región cantábrica: programa experimental para el análisis de huellas de uso en materiales malacológicos", Trabajos de Prehistoria, 67, pp. 211-225.

http://dx.doi.org/10.3989/tp.2010.10037

Cuenca, D.; Gutiérrez-Zugasti, I. y Clemente, I. (2011): "The use of molluscs as tools by coastal human groups: contribution of ethnographical studies to research on Mesolithic and early Neolithic contexts in Northern Spain", Journal of Anthropological Research, 67 (1), pp. 77-102.

GARCÍA DEL BARRIO, I. (1988): Mapa de suelos de la provincia de Cádiz. Cádiz y San Fernando. E. 1: 50.000. Hoja 4. Sevilla: Junta de Andalucía.

GASSIOT, E. (2002): "Análisis funcional y producción en las sociedades cazadoras-recolectoras. Significación de los cambios tecnológicos durante el Mesolítico". En Clemente, I.; Risch, R. y GibajA, J. F. (eds.): Análisis Funcional: su aplicación al estudio de sociedades prehistóricas. BAR Int. Ser., 1073. Oxford: Archaeopress, pp. $31-42$.

GonZález Urquijo, J. E. e IbÁŃNEZ, J. J. (1994): Metodologia de análisis funcional de instrumentos tallados en sílex. Cuadernos de Arqueología, 14. Bilbao: Univ. de Deusto.
Gutiérrez-Zugasti, F. I.; Cuenca, D.; Clemente, I.; González SÁinz, C. y López Quintana, J. C. (2011): "Instrumentos de trabajo y elementos de adorno en conchas de molusco de la cueva de Santimamiñe (Kortezubi, Bizkaia)". En López QuintANA, J. C. (ed.): Excavaciones en la cueva de Santimamiñe. Campañas 2004-2006. Kobie, Serie Excavaciones (1). Vizcaya, pp. 1-16.

LAMMERS, Y. M. (2008): Tracing Traces from Present to past. A funtional analysis of pre-Columbian shell and stone artefacts from Anse à la Gourde and Morel, Guadaloupe, FWI. Amsterdam: Leiden University Press.

MaICAS, R. (2008): "Objetos de concha: algo más que adornos en el Neolítico de la cuenca de Vera (Almería)". En Hernández Pérez, S.; Soler Días, J. A. y López Padilla, J. A. (eds.): IV Congreso del Neolítico Peninsular. Alicante: Diput. Prov.-Museo Arqueológico de Alicante, t. II, pp. 313-319.

Mansur, M. E. y Clemente, I. (2009): “¿Tecnologías invisibles? Confección, uso y conservación de instrumentos de valva en Tierra del Fuego". En Oliva, F.; De Grandis, N. y RodrígueZ, J. (eds.): Arqueología argentina en los inicios de un nuevo siglo (XIV Congreso Nacional de Arqueología Argentina). Rosario: Univ. Nacional de Rosario, vol. 2, pp. 359-367.

Ramos, J.; Castañeda, V.; Domínguez Bella, S.; PIJOAN, J. y ClEMENTE, I. (2005): "La tecnología lítica del asentamiento del embarcadero del río Palmones (Algeciras, Cádiz): captación de recursos, tecnología, función y valoración histórica." En ARIAS, P.; ONTANón, R. y García-Moncó, C. (eds.): Actas del III Congreso del Neolítico en la Peninsula Ibérica. Monografías del Instituto Internacional de Investigaciones Prehistóricas de Cantabria, 1. Santander, pp. 211222.

Semenov, S. A. (1964): Prehistoric Technology. London: Cory Adams and Mackay.

Stuiver, M. y Reimer, P. J. (1993): "Extended 14C database and revised CALIB radiocarbon calibration program", Radiocarbon, 35, pp. 215-230.

StUiver, M.; ReIMER, P. J. y ReIMER, R. W. (2005): "CALIB 5.0." WWW program and documentation (http://radiocarbon/pa/qub.ac.uk/calib).

VARGAS, I. (1987): "La formación económico social tribal", Boletin de Antropología Americana, 15, pp. 15-26.

VIGIÉ, B. (1987): "Essai d'étude méthodologique d'outils sur coquillages de la grotte de Camprafaud (Ferrières-Poussarou, Hérault)", L'Antropologie, 91 (1), pp. 253-272.

Vigié, B. y COURTIN, J. (1986): "Les outils sur coquilles marines dans le Néolithique du Midi de la France", Mesogée, 46, pp. 51-61. 
Vijande, E. (2009): "El poblado de Campo de Hockey (San Fernando, Cádiz): resultados preliminares y líneas de investigación futuras para el conocimiento de las formaciones sociales tribales en la Bahía de Cádiz (tránsito V-IV milenios a.n.e.)", Revista Atlántica-Mediterránea de Prehistoria y Arqueologia Social, 11, pp. 265-284.

- (coord.) (2011): La necrópolis neolitica de Campo de Hockey. La muerte hace seis mil años en la Isla de San Fernando. Catálogo de los materiales expuestos en el Museo Histórico Municipal de San Fernando.
Ayuntamiento de San Fernando, Fundación Municipal de Cultura.

Villalpando, A. y Montañés, M. (2009): "Avance de resultados de las excavaciones arqueológicas realizadas en Set Parralejos", Revista Atlántica-Mediterránea de Prehistoria y Arqueología Social, 11, pp. 257-264.

Zazo, C.; GoY, J. L.; GARCÍA De Domingo, A.; GoNZÁlez, J. y HernáIZ, P. P. (1987): San Fernando. Mapa Geológico de España. IGME. Hoja 11-46. E. 1: 50.000. Madrid. 